\title{
Kathleen Eisenhardt: recipient of the 2012 Global Award for Entrepreneurship Research
}

\author{
Bo Carlsson
}

Accepted: 11 February 2013/Published online: 9 March 2013

(C) The Author(s) 2013. This article is published with open access at Springerlink.com

\begin{abstract}
This article reviews the academic contributions of the 2012 receiver of the Global Award for Entrepreneurship Research, Professor Kathleen Eisenhardt, Stanford Warren Ascherman Professor of Management Science and Engineering at Stanford University. The Global Award consists of 100,000 euro and a statuette by the internationally renowned Swedish sculptor Carl Milles. Eisenhardt's work focuses on strategy, strategic decision making, and innovation in rapidly changing and highly competitive markets. Her work in the entrepreneurship field centers on strategy and organization, especially in technology-based companies, what she refers to as "high-velocity industries". Her main empirical contribution to the entrepreneurship field is her work on 'corporate entrepreneurship'-how existing organizations can remain innovative, including through new venture creation. More generally, Kathleen Eisenhardt's research has bridged the two fields of entrepreneurship research and organization science.
\end{abstract}

Keywords Global Award - Entrepreneurship · Corporate entrepreneurship · Organization · Strategy

JEL classifications $\quad \mathrm{L} 2 \cdot \mathrm{L} 5 \cdot \mathrm{M} 13 \cdot \mathrm{O} 3$

B. Carlsson ( $\square)$

Department of Economics, Weatherhead School of Management, Case Western Reserve University, Cleveland, OH, USA

e-mail: Bo.Carlsson@case.edu

\section{Introduction}

Every year since 1996 the Global Award for Entrepreneurship Research has been given to a scholar who has produced scientific work of outstanding quality and importance, thereby giving a significant contribution to theory-building concerning entrepreneurship and small business development, the role and importance of new firm formation and the role of SMEs in economic development. ${ }^{1}$ The aims of the Award are (1) to highlight the importance of research produced in the areas of entrepreneurship and small business; (2) to further stimulate and promote research within these fields; and (3) to diffuse state-of-the-art research among scholars, policymakers, practitioners, and people involved in small business development.

The domain of entrepreneurship research involves many disciplines such as economics, management/ business administration, sociology, psychology, economic and cultural anthropology, business history,

\footnotetext{
1 The Global Award is a direct continuation of the International Award for Entrepreneurship and Small Business Research first launched in 1996 by The Swedish Entrepreneurship Forum (then Foundation for Small Business Research, FSF) and the Swedish Agency for Economic and Regional Growth. Since 2009 these two organizations have been joined by The Research Institute of Industrial Economics (IFN), thanks to a generous donation by the Swedish industrialist Rune Andersson, Mellby Gård AB. The prize consists of 100,000 euro and a statuette by the internationally renowned sculptor Carl Milles, the "Hand of God."
} 
strategy, marketing, finance, and geography. It encompasses numerous activities (functions) carried out by individuals and/or organizations resulting in new business in either new or existing organizations ultimately yielding economic and/or social benefits in the form of economic growth and improved human welfare. The activities involve risk-taking, pro-activeness, and innovativeness. The analysis can be carried out at various levels (individual or team level, venture and firm level, and macroeconomic level). The socioeconomic environment consisting of institutions, norms, and culture as well as availability of finance, knowledge creation in the surrounding society, economic and social policies, the presence of industry clusters, and geographic parameters, may influence entrepreneurial activities at all levels. Any aspect of entrepreneurship research in this domain can be awarded, such as the environment and the organizations in which entrepreneurship is conducted, the character of the entrepreneur (personality, cognitive and affective aspects), or the role of the entrepreneur and/or the entrepreneurial function in a wider sense (at the level of the community, region, country, industry).

The research domain is illustrated in Fig. 1. The left side in the figure represents the explorative aspects of entrepreneurship, i.e. the role and characteristics of individuals and teams (organizations). The result of these activities is opportunity recognition, innovation and venture creation. On the right side, venture creation can take the form of creation of new organizations or of new activities in existing organizations. The aggregate outcomes in the form of economic growth and human welfare are represented on the far right side. All the activities and outcomes are influenced by one or more dimensions of the socioeconomic environment, including institutions/norms/ culture, knowledge creation, finance, economic and social policies, clusters, and geography. The middle of Fig. 1 represents explorative entrepreneurial activities that lead to the creation of new firms and new activities in existing organizations. The focus is on the functions and outcomes of entrepreneurship at the macroeconomic level.

Each year the Prize Committee for the Global Award for Entrepreneurship Research has the task of selecting a person who has made an outstanding contribution in this broad arena. The winner of the 2012 Award is Kathleen Eisenhardt, Stanford Warren Ascherman Professor of Management Science and
Engineering and Co-Director of the Stanford Technology Ventures Program at the School of Engineering at Stanford University.

The remainder of this article is a review of Eisenhardt's contributions to entrepreneurship research and is organized as follows. The next section summarizes the main themes of Eisenhardt's entrepreneurship research. These themes are then explored in more detail in the subsequent sections. The concluding section summarizes the reasons why Kathleen Eisenhardt is a worthy recipient of the 2012 Award for Entrepreneurship Research.

\section{Eisenhardt's research profile}

Kathleen Eisenhardt is a prolific scholar and her research spans a broad range of topics. She is widely known for her work on strategy, strategic decision making, and innovation in rapidly changing and highly competitive markets. Even though only a portion of Eisenhardt's work can be directly and explicitly labeled as 'entrepreneurship' research, she has made significant contributions to this relatively new and rapidly evolving field.

Kathleen Eisenhardt has also pioneered in building theories from case study research. Her most cited article and arguably her most influential work on entrepreneurship research is her article "Building Theories from Case Study Research," published in the Academy of Management Journal, 1989. This article has been cited more than 17,000 times. The paper describes the entire process of inducting theory using case studies, from problem definition and specifying the research questions, crafting of survey instruments and protocols, gathering data through open-ended interviews, coding and analysis of data in a highly iterative process, and formulating hypotheses to construct validation and reaching closure. It is based on the seminal work by Glaser and Strauss (1967) on the use of grounded theory in qualitative research. This research approach is especially appropriate in new topic areas such as entrepreneurship research. The resultant theory is often novel, testable, and empirically valid. Eisenhardt has used this methodology in many of her papers and certainly in most of the papers reviewed here; it is also being used and frequently cited by entrepreneurship scholars, particularly in the management discipline. 
Fig. 1 Domain of entrepreneurship research

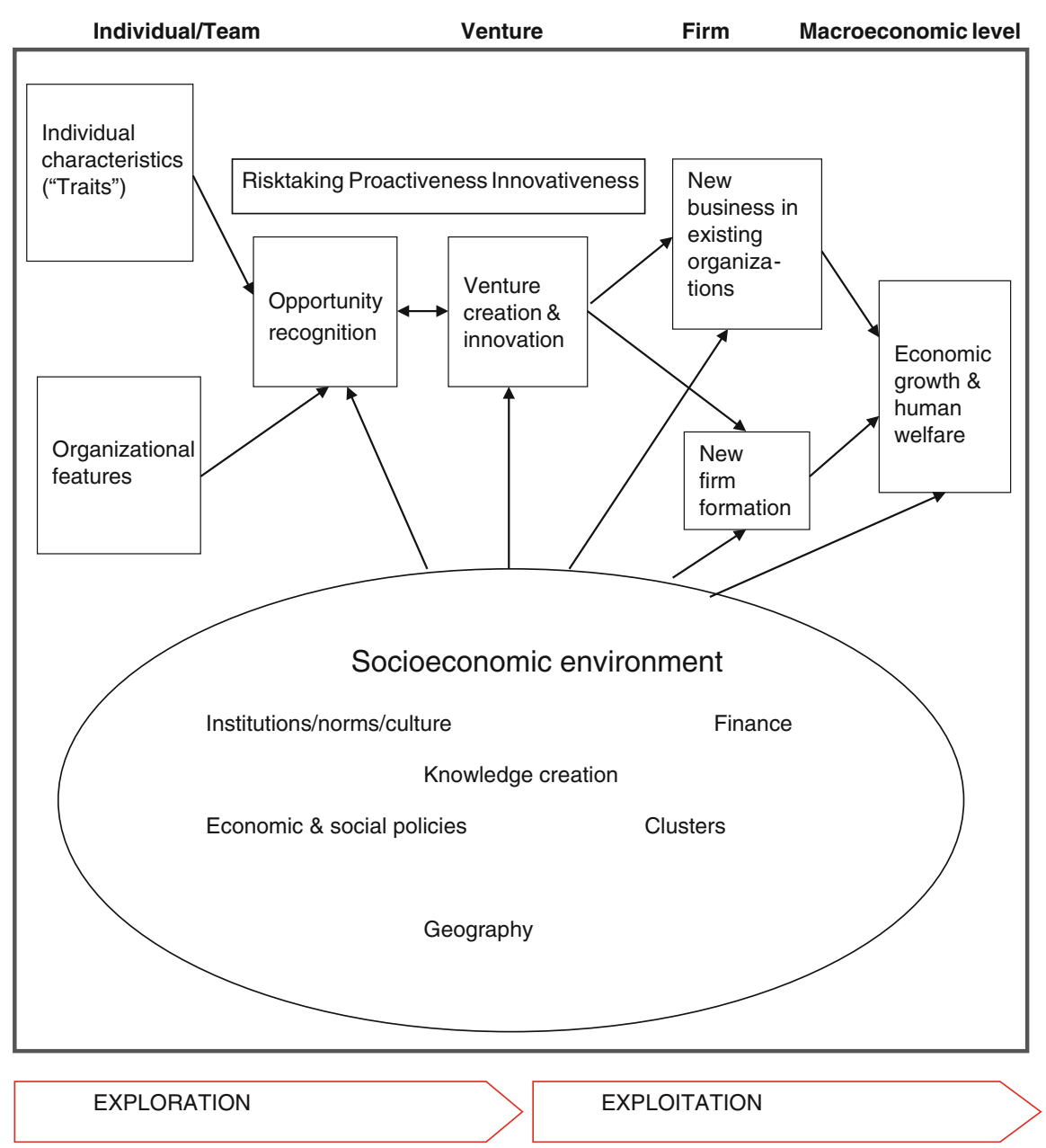

Kathleen Eisenhardt's work in entrepreneurship centers on strategy and organization, especially in technology-based companies in what she refers to as "high-velocity industries" of which the semiconductor industry in Silicon Valley is a prime example.

One of Eisenhardt's main contributions to entrepreneurship research involves the integration of entrepreneurship research into organization science. Her entrepreneurship work is focused primarily on innovation and new venture formation in existing organizations (often referred to as 'corporate entrepreneurship') rather than on de novo firm formation. The key questions addressed are "What are the characteristics of such venture formation?", and "When is new venture formation more likely to occur through incumbent firms rather than through de novo enterprises?".

There are several aspects of entrepreneurial activity in an organizational perspective ('corporate entrepreneurship'). Eisenhardt's contributions here may be grouped under four different themes:

- The influence of the market (technological) environment on the probability of success of new firms.

- The factors influencing the speed with which new products reach the market.

- The role of strategic alliances in entrepreneurial ventures.

- Organizational features of new ventures, especially the role and composition of the top management team (organization theory and design).

\subsection{Market (technology) environment}

One study (Eisenhardt and Schoonhoven 1990) explores organizational growth in technology-based ventures for which the role of technical change in creating differentially attractive resource opportunities is particularly 
germane. The paper examines the growth of young firms and links their organizational features such as topmanagement-team factors to environment, strategy, and growth. The overall premise is that founding environment, strategy, and top-management team have a significant impact on the resource levels and, ultimately, on growth of young firms.

The paper distinguishes between three types of market environment. Emergent markets are stimulated by waves of innovation. Such markets are characterized by low demand and high uncertainty; there is no proven market viability, and the technology may still be uncertain. Distribution channels and sources of supply may be problematic. Emergent markets are difficult for young firms because the timing of commercial takeoff in such markets is difficult to predict, and new firms may not have the resources necessary to survive until the market takes off; financial backers may lose interest. "When takeoff finally happens, the young firms already in the market may be too drained to take advantage of the growth, and they may be constrained by obsolete technology, skills, and physical plant. Worst of all, the market may never become viable." (p. 507) As a result, big and established firms are more likely than new firms to succeed in such founding environments.

In contrast, growth markets provide many resource opportunities for new firms. Such markets are large, products are commercially viable, and customers are aware of the product advantages. This provides ample room for the entry of young firms. On the other hand, mature markets provide limited opportunities for new firms because new firms have few, if any, advantages over their established competitors, and market growth is slow or stagnant.

\subsection{Speed to market}

In a series of papers (Schoonhoven et al. 1990; Eisenhardt 1990; Eisenhardt and Tabrizi 1995; Brown and Eisenhardt 1997; Eisenhardt 1999), Eisenhardt examines the impact of technological innovation, entrepreneurial and organizational characteristics, and environmental variables on a significant entrepreneurial event, e.g. the number of months from its date of founding that it takes a new organization to ship its first product for revenues. She also examines the influence of organizational conditions (innovation, structure, resources, and organizational members) and environmental circumstances (competitors, investors, and mimetic pressures) on the speed with which new organizations develop their first products for market.

One of the findings in this research is that organizations that undertook relatively low levels of technological innovation, had low monthly expenditures, whose founding organization structures included both a manufacturing and a marketing position, that had more competitors in the marketplace, and were founded in the Silicon Valley region of the United States shipped their first product for revenues significantly faster than other new ventures.

The factors that were found to speed products to market were:

1. The degree of technological innovation: Substantial technological innovation lengthens development times and reduces the speed with which first products reach the marketplace.

2. A founding structure that contains specialized functions such as manufacturing and marketing positions at a senior level in the organization were significantly faster in speeding products to market.

3. Availability of ample financial resources.

4. A market environment characterized by a large number of competitors.

5. Being founded in the region that constitutes the geographical center of the new venture's industry.

Another dimension affecting the success of new ventures is speed in decision-making. Speed matters in that a strategy that takes too long to formulate is at least as ineffective as the wrong strategy. But, how do decision makers make fast, yet high-quality, strategic choices? Eisenhardt (1990) shows that: (1) they maintain constant watch over real-time operating information and rely on quick, comparative analysis to speed cognitive processing; (2) they favor approaches to conflict resolution that are rapid and yet maintain group cohesion; and (3) their reliance on the private advice of experienced counselors and on integration with other decisions bolsters their confidence to decide quickly in the face of big stakes and high uncertainty.

This research also shows that successful firms in high-velocity markets use four approaches to create strategy. Management teams (1) build collective intuition; (2) stimulate conflict by assembling diverse teams; (3) focus on maintaining decision pace, not 
pushing decision speed; and (4) take a negative view on politicking: collaboration, not competition among team members.

Eisenhardt and Tabrizi (1995) studied how to accelerate adaptive processes. They used two different theoretical models for firms' achieving fast adaptation through product innovation. The compression model assumes a well-known, rational process and relies on squeezing together or compressing the sequential steps of such a process. In contrast, the experiential model assumes an uncertain process and relies on improvisation, real-time experience, and flexibility. The findings were that using an experiential strategy of multiple design iterations, extensive testing, frequent project milestones, a powerful project leader, and a multifunctional team accelerates product development. In contrast, the compression strategy of supplier involvement, use of computer-aided design, and overlapping development steps describes fast pace only for mature industry segments. The results also show that planning and rewarding for schedule attainment are ineffective ways of accelerating pace.

\subsection{Alliances}

Another stream of Eisenhardt's research examines why firms form strategic alliances and why such alliances matter in entrepreneurial ventures. The main finding in Eisenhardt and Schoonhoven (1996) is that alliances are formed either when firms are in vulnerable strategic positions (for example, in difficult market conditions requiring risky firm strategies) for which they need additional resources that alliances can provide to compete effectively, or when firms are in strong social positions such that they have the resources necessary to know, attract, and engage partners. The top management characteristics that affect the rate of alliance formation are found to be the following. Firms with top management teams that are large, experienced, and well-connected through former employers and high-level previous jobs form product development alliances at higher rates than other firms.

Another paper (Katila et al. 2008) explores the dangers inherent in forming alliances with partners with high potential for misappropriation ("corporate sharks") rather than less risky partners. The findings show that entrepreneurs take the risk when they need resources that established firms uniquely provide (such as financial resources and manufacturing capability) and when they have effective defense mechanisms to protect their own resources (e.g., secrecy and timing). Overall, the findings show that tie formation is a negotiation that depends on resource needs, defense mechanisms, and alternative partners. A key point is that highly desirable new firms may actually be the more powerful partner and dominant decision maker in corporate investment relationships.

We found that new firms are more likely to form corporate investment relationships when the push for ties is amplified by multiple resource needs-outsized financial resources and complementary manufacturing resources that established firms uniquely provide [...] We found that manufacturing resources are more significant than marketing resources [...] Contrary to our expectations, we found that financial resources, with their greater fungibility, are the most significant resources for tie formation. For new firms, this preference is clear. Financial resources offer very desirable flexibility and, unlike the use of complementary resources, do not involve sensitive intellectual property. But for the corporation, this preference is not so clear. (Katila et al. 2008, p. 324)

Ozcan and Eisenhardt (2009) go further in examining how firms originate high-performing portfolios of alliances (i.e., portfolios that are likely to improve firm performance). They find that:

- Executives in firms with high-performing portfolios visualize their portfolios in the context of an entire network, not as a series of single ties. Thus, they have a holistic understanding of possible interdependencies among types of firms, the location of unconnected firms, and the presence of industry uncertainties.

- In contrast, executives in firms with low-performing portfolios have a simplistic view in which they are constrained by given dyadic interdependencies (e.g., buyer-supplier), existing social relationships, and a myopic understanding of the industry that emphasizes local ties.

- Firms that engage in strategic actions based on making multiple simultaneous ties within a holistic industry understanding are more likely to create superior portfolios. 
- Portfolios and networks are not simply exogenous creations of path-dependent trajectories. Rather, they are endogenously crafted by actors who choose to form ties with each other. Overall, portfolio success goes to those with more comprehensive views of their industry and more complete repertoires of strategies.

Davis and Eisenhardt (2011) examine why some inter-organizational relationships produce technological innovations while others do not. They find, among other things, that rotating leadership among the partners induces innovation.

\subsection{Organization theory}

As noted above, Eisenhardt's research emphasizes the role and composition of the top management team in new venture creation, particularly the importance of having competence in various functions such as manufacturing and marketing represented on the team. Inevitably, such heterogeneity raises the probability of disagreement among the members of the top management team as executives struggle with making highstakes choices under conditions of ambiguity and uncertainty. Eisenhardt et al. (1997) examined how top management teams manage to deal with such conflicts. Recommendations based on this research are to build a heterogeneous team, to create frequent interactions within that team, to cultivate a distinct symphony of roles around fundamental tensions within managing, and to use multiple-lens tactics such as competitor role playing and multiple alternatives to provide unexpected vantage points on key issues. Pelled et al. (1999) present and test an integrative model of the relationships among diversity, conflict, and performance. Their findings show that diversity shapes conflict and that conflict, in turn, shapes performance. Functional background diversity drives task conflict, but multiple types of diversity drive emotional conflict. Race and tenure diversity are positively associated with emotional conflict, while age diversity is negatively associated with such conflict. Task routines and group longevity moderate these relationships. The results also show that task conflict has more favorable effects on cognitive task performance than does emotional conflict. Overall, these patterns suggest a complex link between work group diversity and work group functioning.
Graebner and Eisenhardt (2004) present an interesting and novel perspective on governance in entrepreneurial firms. In contrast to the prior acquisitions literature, which emphasizes the buyer's perspective, the authors examined the seller's perspective. This has important implications for understanding both the acquisition process and, more broadly, corporate governance in successful firms. Using a multiple-case, inductive study of 12 technology-based ventures, the authors found that acquisition occurs when sellers are pushed toward acquisition by difficult strategic hurdles, such as a chief executive search or funding round, and by strong personal motivations for sale, such as past failures and investments by friends. They reframe acquisition as "courtship" (a process of getting acquainted and exploring common goals) between buyer and seller, and corporate governance as a "syndicate," indicating joint decision making with some common goals.

Knowledge acquisitions are particularly likely to be courtships. Because much of the value of these acquisitions lies with individuals, heavyhanded takeover tactics are likely to destroy value by encouraging these 'resources' to leave. Also, in knowledge acquisitions, buyers often stretch the negotiation period in order to better understand the match, an action consistent with a courtship [...] Finally, there are several types of companies for which the non-price factors suggested by courtship may be important. These include family firms, in which family pride and social responsibility may be relevant. (Graebner and Eisenhardt 2004, p. 7)

Sellers are also more likely to be pulled toward acquisition by attractive buyers that offer synergistic combination potential and organizational rapport, factors usually associated with the long-term interests of buyers. Together, "courtship" and "syndicate" suggest a behaviorally informed account of organization that differs from the standard account of price and self-interest as drivers of acquisitions.

In a few related papers (esp., Helfat and Eisenhardt 2004; Santos and Eisenhardt 2005, 2009), Eisenhardt has gone further in exploring the dynamics of diversification and the relationships between organizational boundaries and theories of organization. In this research she takes a more behavioral approach than the conventional view which is based on transaction 
cost economics and related efficiency perspectives. But these papers do not fall directly in the entrepreneurship research domain and are therefore not reviewed here. She has also published many articles on corporate strategy, decision-making processes, and dynamic capabilities that are relevant for entrepreneurship research but that cannot be categorized explicitly in that domain.

\section{Conclusion}

The inductive, exploratory approach that characterizes most of Kathleen Eisenhardt's research has opened up new avenues of research in the entrepreneurship domain. Her main theoretical contribution is the integration of entrepreneurship research into organization science. Her work links the domain of entrepreneurship research to the fields of dynamic capabilities, strategy and decision making processes, and organization theory and design. She has looked at how strategic decisions are taken, especially with respect to how new ventures are formed and how they forge linkages with competitors, how they grow and survive through innovation as well as by shaping the rules of competition.

Her main empirical contribution to the entrepreneurship field is her work on 'corporate entrepreneurship'-how existing organizations can remain innovative, including through new venture creation. She has examined how established organizations can introduce a continuous stream of novel products and services through better new product development processes as well as more efficient ways of organizing their activities. This research has significant policy implications. Most policies intended to stimulate entrepreneurship focus on de novo firm formation and small business. While these are important, Eisenhardt's work shows that innovative and entrepreneurial activities within existing enterprises can also be drivers of economic growth and development.

In sum, Kathleen Eisenhardt has made substantial, original and influential contributions methodologically, theoretically and empirically that establish entrepreneurship research more solidly in both the management and the economics literature and that have important policy implications. She is a worthy recipient of the 2012 Global Award for Entrepreneurship Research.
Open Access This article is distributed under the terms of the Creative Commons Attribution License which permits any use, distribution, and reproduction in any medium, provided the original author(s) and the source are credited.

\section{References}

Brown, S. L., \& Eisenhardt, K. M. (1997). The art of continuous change linking complexity theory and time-paced evolution in relentlessly shifting organizations. Administrative Science Quarterly, 42(1), 1-34.

Davis, J. P., \& Eisenhardt, K. M. (2011). Rotating leadership and collaborative innovation: Recombination processes in symbiotic relationships. Administrative Science Quarterly, 56(2), 159-201.

Eisenhardt, K. M. (1990). Speed and strategic choice: How managers accelerate decision making. California Management Review, 32(3), 39-55.

Eisenhardt, K. M. (1999). Strategy as strategic decision making. Sloan Management Review, 40(3), 65-72.

Eisenhardt, K. M., Kahwajy, J. L., \& Bourgeois III, L. J. (1997). Conflict and strategic choice: How top management teams disagree. California Management Review, 39(2), 42-62.

Eisenhardt, K. M., \& Schoonhoven, C. B. (1990). Organizational growth: Linking founding team, strategy, environment, and growth among U.S. semiconductor ventures, 1978-1988. Administrative Science Quarterly, 35(3), 504-529.

Eisenhardt, K. M., \& Schoonhoven, C. B. (1996). Resourcebased view of strategic alliance formation: Strategic and social effects in entrepreneurial firms. Organization Science, 7(2), 136-150.

Eisenhardt, K. M., \& Tabrizi, B. N. (1995). Accelerating adaptive processes: Product innovation in the global computer industry. Administrative Science Quarterly, 40(1), 84-110.

Glaser, B. G., \& Strauss, A. L. (1967). The discovery of grounded theory: Strategies of qualitative research. London: Wiedenfield and Nicholson.

Graebner, M. E., \& Eisenhardt, K. M. (2004). The seller's side of the story: Acquisition as courtship and governance as syndicate in entrepreneurial firms. Administrative Science Quarterly, 49(3), 366-403.

Helfat, C. E., \& Eisenhardt, K. M. (2004). Inter-temporal economies of scope, organizational modularity, and the dynamics of diversification. Strategic Management Journal, 25(13), 1217-1232.

Katila, R., Rosenberger, J. D., \& Eisenhardt, K. M. (2008). Swimming with sharks: Technology ventures, defense mechanisms and corporate relationships. Administrative Science Quarterly, 53(2), 2295-2332.

Ozcan, P., \& Eisenhardt, K. M. (2009). Origin of alliance portfolios: Entrepreneurs, network strategies, and firm performance. Academy of Management Journal, 52(2), 246-279.

Pelled, L. H., Eisenhardt, K. M., \& Xin, K. R. (1999). Exploring the black box: An analysis of work group diversity, conflict, and performance. Administrative Science Quarterly, 44(1), 1-28. 
Santos, F. M., \& Eisenhardt, K. M. (2005). Organizational boundaries and theories of organization. Organization Science, 16(5), 491-508.

Santos, F. M., \& Eisenhardt, K. M. (2009). Constructing markets and shaping boundaries: Entrepreneurial power in nascent fields. Academy of Management Journal, 52(4), 643-671.
Schoonhoven, C. B., Eisenhardt, K. M., \& Lyman, K. (1990). Speeding products to market: Waiting time to first product introduction in new firms. Administrative Science Quarterly, 35(1), 177-207. 